\title{
Recent advances in medical treatment and percutaneous, transapical and surgical interventions in aortic-valve stenosis Alik Sagie $^{1,2 *}$ and Danny Dvir ${ }^{1,2}$
}

Addresses: ${ }^{1}$ Echocardiographic Laboratory and Valvular Clinic, Department of Cardiology, Rabin Medical Center, 39 Jabotinski St, Petah Tikva 49100, Israel; ${ }^{2}$ Sackler Faculty of Medicine, Tel Aviv University, Ramat Aviv 69978, Israel

*Corresponding author: Alik Sagie (asagie@post.tau.ac.il)

FI000 Medicine Reports 2009, I:26 (doi: 10.3410/MI-26)

The electronic version of this article is the complete one and can be found at: http://FI000.com/Reports/Medicine/content/I/26

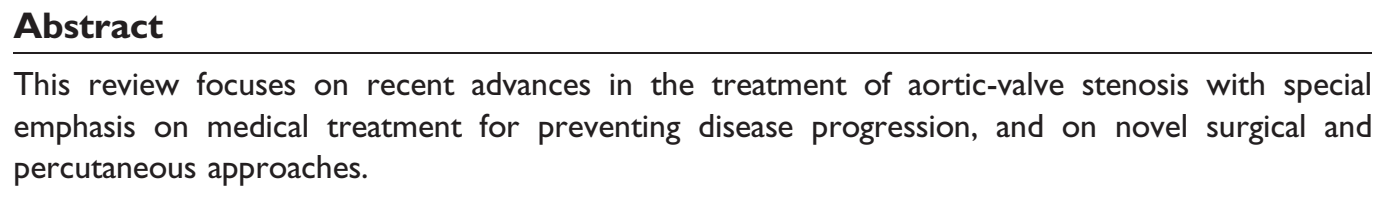

\section{Introduction and context}

Aortic stenosis (AS) is the most common native valve disease at present. It is the third most common cardiovascular disease after hypertension and coronary artery disease.

The first epidemiologic study evaluating the prevalence of AS in Finland revealed the prevalence of severe AS (AVA $\leq 0.8 \mathrm{~cm}^{2}$ ) in $2.9 \%$ of elderly over 75 years of age, mild aortic valve calcification in $40 \%$ and severe calcification in $13 \%$ [1].

Currently, AS is also the second most common indication for cardiac surgery, and the most common indication for valve surgery. In the European registry for valvular heart disease it was found that AS constitutes $43 \%$ of all valve diseases [2]. There are two important reasons for this high prevalence: first, about $2 \%$ of the population is born with a bicuspid aortic valve; and second, the ageing population is reaching the stage where significant degenerative aortic valve disease is developing. Although AS is associated with substantial clinical consequences, until recently there was no effective therapy to treat it other than surgical aortic valve replacement.

\section{Recent advances}

Effect of statins on the progression of aortic valve stenosis Recent advances in the pathophysiology of AS indicate that calcific AS is an active disease process that resembles atherosclerosis and shares the same risk factors. An active atherosclerotic-type pathophysiology involving oxidative stress, inflammation, and endothelial dysfunction in aortic valves has been induced in mice by hypercholesterolaemia, and inhibited by administering HMG-CoA reductase inhibitors (statins) [3]. Consequently, a hypothesis was developed proposing that AS could be a preventable disease, or at least that its progression could be slowed by medical interventions that are effective in slowing or reversing atherosclerosis. Several retrospective studies have suggested that statin therapy may slow the progression of AS as measured by the annual change per year in aortic valve area. Novaro et al. [4], for example, found that the decrease in aortic valve area for a group not treated with statins was $0.11 \pm 0.18 \mathrm{~cm}^{2}$, compared to $0.06 \pm 0.16 \mathrm{~cm}^{2}$ for those treated with statins $(P=0.030)$.

These findings and existing experimental data were the driving force to conduct prospective randomized studies to resolve this important question. In the past several years, three completed prospective studies on the effect of statin therapy on AS progression have been published. The first prospective (non-randomized), open-label 
study was the Rosuvastatin Affecting Aortic Valve Endothelium (RAAVE) study [5]. In this study, echocardiographic, serum lipid, and inflammatory marker determinations were used at baseline and every 6 months for 18 months to evaluate outcomes in 121 patients with asymptomatic moderate to severe AS (aortic valve area 1.0-1.5 $\mathrm{cm}^{2}$ ) who were treated with or without rosuvastatin. This study suggested that rosuvastatin treatment slowed the progression of AS, including hemodynamic indices of progression. It was the first prospective study that showed the potential of medical treatment to slow progression of asymptomatic AS. However, this study was limited by being a nonrandomized, observational study.

The second important study was the Scottish Aortic Stenosis and Lipid Lowering Trial, Impact on Regression (SALTIRE) [6], a randomized, double blind, placebocontrolled trial with a median follow-up of 25 months. In this study, 155 patients with calcific AS and aortic jet velocity $<2.5 \mathrm{~m} / \mathrm{s}$ were treated with either atorvastatin $80 \mathrm{mg} /$ day $(\mathrm{n}=77)$ or placebo $(\mathrm{n}=78)$. In contrast to the RAAVE study, it did not detect a short-term impact of statins on echocardiographic progression of AS or on aortic valve calcium score. The SALTIRE investigators concluded that intensive lipid-lowering therapy did not slow the progression of calcific AS or induce its regression. However, the investigators could not exclude a small reduction in the rate of AS progression or a significant reduction in major clinical endpoints. Also, nearly $25 \%$ of the study population in the atorvastatin group and $22 \%$ in the placebo group had severe AS to begin with and in these patients the disease stage may have been too advanced to be affected by statin therapy within the study's duration.

The third study, the Simvastatin and Ezetimibe in Aortic Stenosis (SEAS) study [7], was a randomized, double blind trial involving 1,873 patients with mild to moderate asymptomatic AS. The patients received either $40 \mathrm{mg}$ simvastatin plus $10 \mathrm{mg}$ ezetimibe or placebo daily. The primary outcome was a composite outcome of combined aortic-valve events and ischemic events. During a median follow-up of 52.2 months, simvastatin and ezetimibe did not reduce the composite outcome. Statin therapy reduced the incidence of ischemic cardiovascular events but not events related to AS. Interestingly, cancer occurred more frequently in the simvastatin-ezetimibe group.

\section{Apicoaortic conduit bypass surgery}

Conventional aortic valve replacement surgery mandates the use of cardiopulmonary bypass, ascending aortic crossclamping, aortotomy, debridement of the diseased valve, and cardioplegic cardiac arrest. An alternative surgical approach has been suggested in which a conduit containing a prosthetic valve relieves AS by shunting blood from the apex of the left ventricle to the descending thoracic aorta (apicoaortic conduit bypass surgery). This surgical approach has been applied sporadically to high-risk adult patients with acquired AS, with just over 100 reported cases in the literature [8]. Recently, Gammie et al. [9] described a series of 31 highrisk AS patients treated with apicoaortic conduit bypass surgery; 22 patients $(71 \%)$ were undergoing re-operation with patent coronary bypass grafts, and five $(16 \%)$ had a porcelain ascending aorta. Postoperative echocardiographic assessment demonstrated that a mean of $72 \%$ of cardiac output flowed through the bypass conduit. The relief of left ventricular outflow tract obstruction was commonly associated with a downgrading of the degree of mitral regurgitation and left ventricular function was preserved. Importantly, in this high-risk patient group, surgical complications were uncommon (only one patient required temporary postoperative hemodialysis and only one patient experienced stroke); however, median postoperative survival was only 870 days, similar to the natural history of unoperated symptomatic AS. This approach is an addition to the armamentarium of therapies for symptomatic AS patients with a high surgical risk and will be further examined in the future.

\section{Percutaneous aortic valve implantation}

As many as one-third of elderly patients with symptomatic AS are not referred for surgery, usually due to high surgical risk or patient refusal. Unfortunately, percutaneous balloon valvuloplasty is unsatisfactory with high recurrence rates. In 2002, Cribier performed the first percutaneous aortic valve implantation (PAVI), opening a new era in AS management [10].

Early implants were performed using Cribier-Edwards valves (Edwards Lifesciences, Irvine, California, USA), which are composed of three leaflets of animal pericardium sutured to a balloon-inflated stent 23 or $26 \mathrm{~mm}$ in diameter. Cribier et al. [11] described the first 27 patients treated by PAVI with the Edwards valve, 23 with the antegrade approach and four with the retrograde approach. All were elderly, with severe co-morbidities, and ineligible for conventional therapy ('no-option' patients). After the procedure, mean valve area increased to $1.7 \mathrm{~cm}^{2}$, yielding a small but significant improvement in global function of the left ventricle. Importantly, there were no deaths directly related to the procedure. Afterwards, Webb et al. [12] reported the outcome of the first 50 high surgical risk severe symptomatic AS patients treated with the Edwards 
Figure I. The Edwards SAPIEN transcatheter heart valve

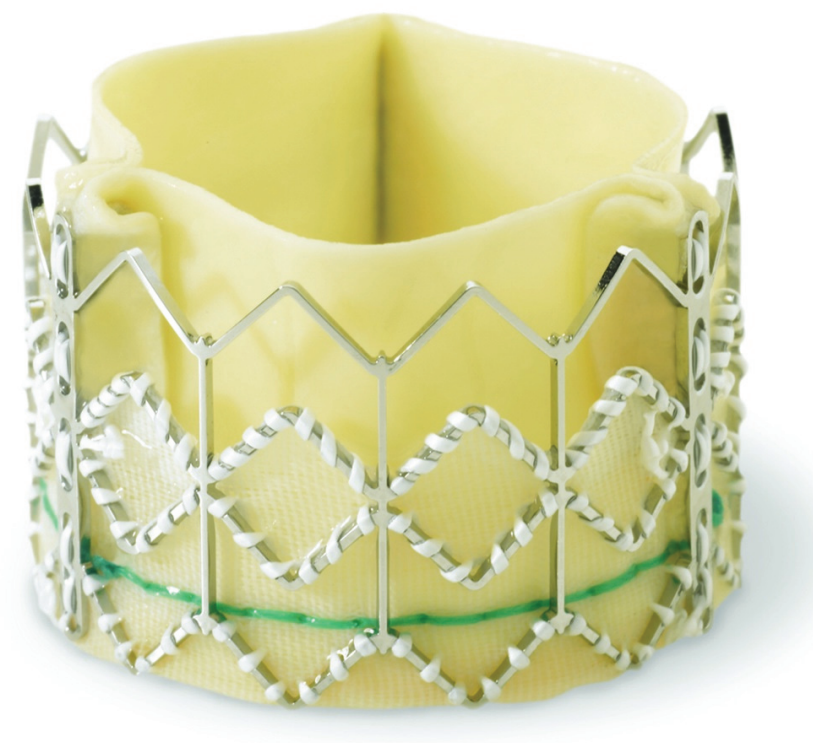

A bovine pericardial valve is sewn within a stainless steel frame. Image provided by Edwards Lifesciences, Irvine, California.

valve implant in Vancouver, Canada, all with the retrograde approach. PAVI was successful in $86 \%$ of patients. On long-term follow-up of 1 year, and up to 2 years, there was not a single case of valve restenosis or malfunction. The mortality rate was $12 \%$ in the first month after the procedure, which was lower than the $28 \%$ predicted mortality according to the patients' preprocedural EuroSCOREs (European System for Cardiac Operative Risk Evaluation). Another important finding in the study of Webb et al. was the difference between patients treated at the beginning of the learning curve and those treated later in terms of procedural success (76 versus 96\%) and 1-month mortality (16 versus $8 \%$ ), indicating the importance of physician experience. Currently, more than 1,000 patients have been treated using the PAVI technique and the CribierEdwards valve, which was slightly modified and is now called the Edwards SAPIEN valve (Figure 1).

The CoreValve system for percutaneous aortic valve replacement (CoreValve Inc, Irvine, CA, USA), also called ReValving technology, is composed of a valve encircled by a 50-53 mm-long frame (depending on valve size) (Figure 2). The CoreValve is self-expandable and intended for mitigation of paravalvular leak and increased durability, although post implantation frame remodelling by means of balloon expansion during use is not uncommon [13]. The possibility to remodel the system after implantation may decrease the risk of perivalvular leak. Because of the self-expanding feature, the suggested use of the system might be extendable to patients who underwent prior surgical biologic valve replacement ('ReDo ${ }^{\mathrm{TM}{ }^{\prime}}$ procedure) [14]. If physicians were able to effectively perform PAVI inside a degenerative implanted biologic valve, the use of biologic valves for aortic valve replacement may increase, because valve malfunction could be treated without the need for redoing surgery. The current (third generation) model has been significantly improved and its delivery catheter has a diameter of only $18 \mathrm{Fr}$. The implantation results of the second- and third-generation systems in 86 patients in several centers in Germany and Canada have been published [15]. Most patients were women, selected because of the small size of the implanted valve, with a mean age of 82 years and a high mean EuroSCORE of $21.7 \%$. The procedural success rate was $88 \%$. There was a dramatic improvement in hemodynamic parameters, including an increase in valve area to $1.7 \mathrm{~cm}^{2}$. Valve regurgitation worsened in only a minority of cases. In the first month after the procedure the mortality rate was $12 \%$; half of these deaths occurred in the first 2 days. Stroke occurred in 10\%. Furthermore, urgent cardiac surgery to release the device was necessary in $6 \%$ of patients. At the time of preparing the present review, more than 3,000 patients had been treated with the CoreValve framed valve. According to currently unpublished results, the procedural success rate for the 18 Fr device is $98 \%$, with only $0.7 \%$ of patients requiring aortic valve replacement surgery in the first postprocedural month.

The transapical approach requires a team consisting of cardiac surgeons and interventional cardiologists $[16,17]$. After a left anterolateral intercostal incision is made to expose the cardiac apex, the delivery system is inserted into the left ventricular cavity and the valve is implanted (Figure 3). This approach is more invasive than those discussed above. The transapical approach has several important advantages. First, there is no delivery of the system via the peripheral vessels, the ascending aorta, or several cardiac chambers, with attendant risks. Second, unlike conventional valve replacement, there is no need for cardiopulmonary bypass or manipulation in the ascending aorta, potentially decreasing the risk of periprocedural stroke. In a recent report on their experience with this method in patients with severe co-morbidity (EuroSCORE 31\%), Walther et al. [18] described no procedural failures and excellent hemodynamics in all cases after several months' follow-up. There were no procedure-related deaths or strokes. Recently, Zierer et al. [19] reported on 26 patients treated with this approach. The EuroSCORE-predicted risk for mortality was $36.5 \%$. All valves were successfully deployed at the target and there were only minor 
Figure 2. The CoreValve device

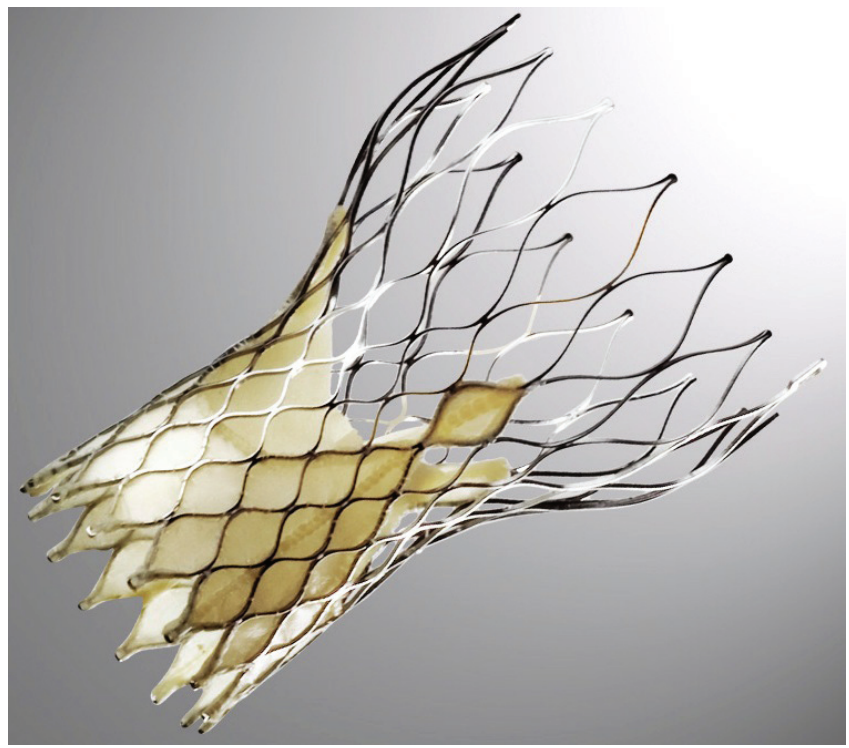

A self-expanding Nitinol frame within which is mounted a trileaflet tissue valve. Image provided by CoreValve Inc, Irvine, California.

paravalvular leakages. Thirty-day mortality was 15\% $(n=4)$. There were two cases of conversion to open surgery. In two patients, the left main stem was partially obstructed by the native valve and required stent angioplasty. During this past year, this approach has been used in several centers worldwide.

\section{Implications for clinical practice} Effect of statins on the progression of aortic valve stenosis Several retrospective and one non-randomized study (RAAVE) have suggested that statin therapy may slow the progression of AS, but the only two available large prospective randomized double blinded studies did not show any effect of high-dose statin therapy on AS progression. Therefore, the data we currently have are contradictory but tend to suggest that statin therapy has no significant effect on the natural history of AS. However, we should await the results of larger randomized studies (ASTRONOMER, AORTICA 1, STAAT and STOP-AS) with longer follow-up, which hopefully will resolve this important issue. Importantly, most of these studies were performed on patients with moderate or severe AS. It might be that statin therapy may be more effective if it is started at a very early stage of the disease when patients have only mild AS or even only nonobstructive aortic valve calcification.
Figure 3. Illustration of transapical valve implantation

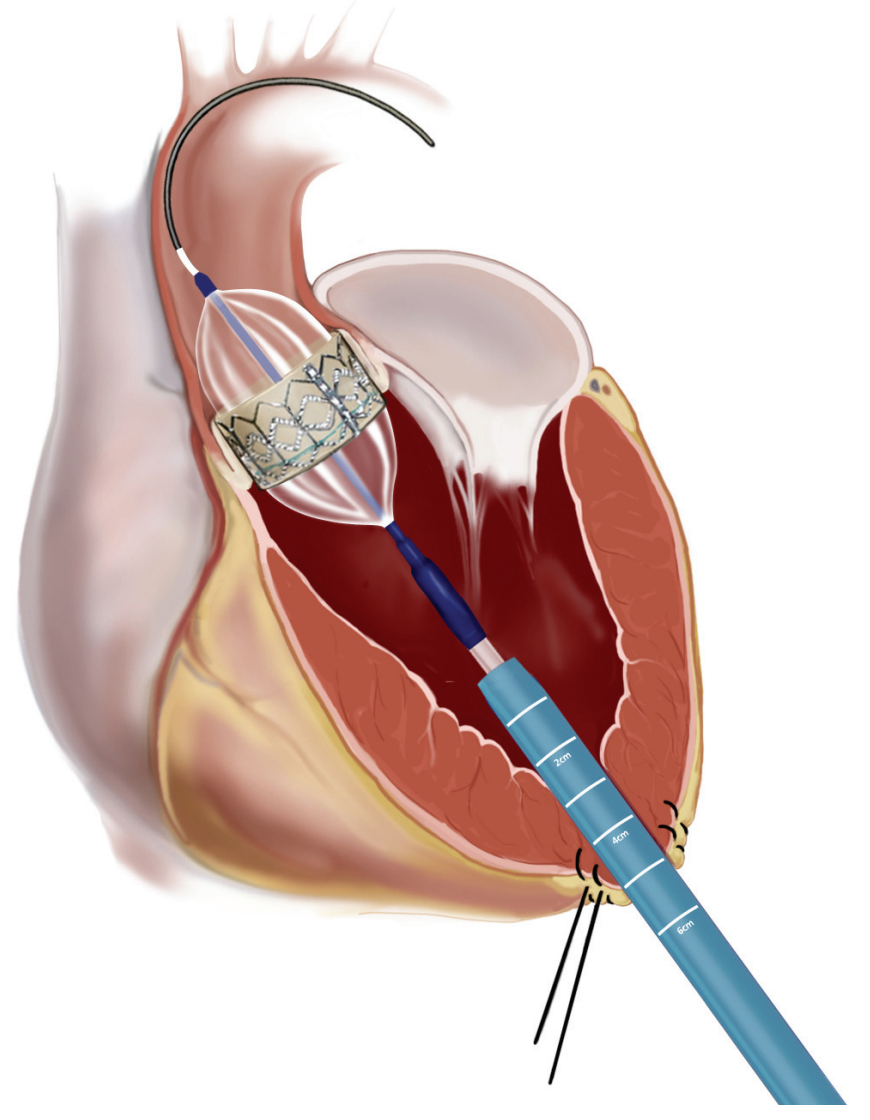

Image provided by Edwards Lifesciences, Irvine, California.

\section{Percutaneous aortic valve implantation}

Although still in its early stages, and not yet sufficiently viable to replace conventional methods in low-risk patients, percutaneous treatment of AS holds promise for providing symptomatic relief and, possibly, longevity to patients who are ineligible for surgery due to their high surgical risk. Preliminary studies show that PAVI is both feasible and effective in elderly patients with AS in the short and medium term. However, the procedure is still associated with significant adverse effects and mortality, and the long-term results are still unknown. Therefore, the procedure is not yet ready to replace conventional surgical aortic valve replacement in low risk patients and at this time is reserved for high surgical risk candidates.

\section{Abbreviations}

AORTICA 1, Double Blind Randomized Phase IV Clinical Trial to Evaluate the Efficacy of Fluvastatin on Inflammatory Markers in the Haemodynamic Progression of Degenerative Aortic Stenosis; AS, aortic stenosis; ASTRONOMER, Aortic Stenosis Progression 
Observation: Measuring Effects of Rosuvastatin; EuroSCORE, European System for Cardiac Operative Risk Evaluation; PAVI, percutaneous aortic valve implantation; RAAVE, Rosuvastatin Affecting Aortic Valve Endothelium; SALTIRE, Scottish Aortic Stenosis and Lipid Lowering Trial, Impact on Regression; STAAT, Statin Therapy in Asymptomatic Aortic Stenosis; STOPAS, Stop Aortic Stenosis.

\section{Competing interests}

The authors declare that they have no competing interests.

\section{References}

I. Lindroos M, Kupari M, Heikkila J, Tilvis R: Prevalence of aortic valve abnormalities in the elderly: an echocardiographic study of a random population sample. J Am Coll Cardiol 1993, 2I:I220-5.

2. lung B, Baron G, Butchart EG, Delahaye F, Gohlke-Bärwolf C, Levang OW, Tornos P, Vanoverschelde JL, Vermeer F, Boersma E, Ravaud P, Vahanian A: A prospective survey of patients with valvular heart disease in Europe: the Euro Heart Survey on valvular heart disease. Eur Heart J 2003, 24:1231-43.

3. Weiss RM, Ohashi M, Miller JD, Young SG, Heistad DD: Calcific aortic valve stenosis in old hypercholesterolemic mice. Circulation 2006, I I 4:2065-9.

4. Novaro GM, Tiong IY, Pearce GL, Lauer MS, Sprecher DL, Griffin BP: Effect of hydroxymethylglutaryl coenzyme $A$ reductase inhibitors on the progression of calcific aortic stenosis. Circulation 200I, 104:2205-9.

5. Moura LM, Ramos SF, Zamorano JL, Barros IM, Azevedo LF, RochaGoncalves F, Rajamannan NM: Rosuvastatin affecting aortic valve endothelium to slow the progression of aortic stenosis. J Am Coll Cardiol 2007, 49:554-6I.

\section{Changes Clinical Practice}

FI000 Factor 6.6 Must Read

Evaluated by Jerome Fleg 29 Mar 2007, Alik Sagie II Apr 2007,

Raphael Rosenhek 16 May 2007, John Paraskos 16 Jul 2007

6. Cowell SJ, Newby DE, Prescott RJ, Bloomfield P, Reid J, Northridge DB, Boon NA, Scottish Aortic Stenosis and Lipid Lowering Trial, Impact on Regression (SALTIRE) Investigators: A randomized trial of intensive lipid-lowering therapy in calcific aortic stenosis. $N$ Engl J Med 2005, 352:2389-97.

FI000 Factor 6.0 Must Read

Evaluated by Chim Lang 21 Aug 2006

7. Rossebø AB, Pedersen TR, Boman K, Brudi P, Chambers JB, Egstrup K, Gerdts E, Gohlke-Bärwolf C, Holme I, Kesäniemi YA, Malbecq W, Nienaber CA, Ray S, Skjaerpe T, Wachtell K, Willenheimer R; SEAS Investigators: Intensive lipid lowering with simvastatin and ezetimibe in aortic stenosis. N Engl J Med 2008, 359:1343-56.

FI000 Factor 6.4 Must Read

Evaluated by John Paraskos 10 Oct 2008, Jerome Fleg 16 Oct 2008

8. Gammie JS, Brown JW, Brown JM, Poston RS, Pierson RN 3rd, Odonkor PN, White CS, Gottdiener JS, Griffith BP: Aortic valve bypass for the high-risk patient with aortic stenosis. Ann Thorac Surg 2006, 81:1605-10.

9. Gammie JS, Krowsoski LS, Brown JM, Odonkor PN, Young CA, Santos MJ, Gottdiener JS, Griffith BP: Aortic valve bypass surgery: midterm clinical outcomes in a high-risk aortic stenosis population. Circulation 2008, I I 8: | 460- I 466.

FI000 Factor 3.0 Recommended

Evaluated by John Paraskos 22 Dec 2008

10. Cribier A, Eltchaninoff $H$, Bash A, Borenstein N, Tron C, Bauer F, Derumeaux G, Anselme F, Laborde F, Leon MB: Percutaneous transcatheter implantation of an aortic valve prosthesis for calcific aortic stenosis: first human case description. Circulation 2002, 106:3006-8.

II. Cribier A, Eltchaninoff H, Tron C, Bauer F, Agatiello C, Nercolini D, Tapiero S, Litzler PY, Bessou JP, Babaliaros V: Treatment of calcific aortic stenosis with the percutaneous heart valve mid-term follow-up from the initial feasibility studies: the French experience. J Am Coll Cardiol 2006, 47:1214-23.

12. Webb JG, Pasupati S, Humphries K, Thompson C, Altwegg L, Moss R, Sinhal A, Carere RG, Munt B, Ricci D, Ye J, Cheung A, Lichtenstein SV: Percutaneous transarterial aortic valve replacement in selected high-risk patients with aortic stenosis. Circulation 2007, I I 6:755-63.

FI000 Factor 3.0 Recommended

Evaluated by Wilbert Aronow 12 Nov 2007

13. Grube E, Schuler G, Buellesfeld L, Gerckens U, Linke A, Wenaweser P, Sauren B, Mohr FW, Walther T, Zickmann B, Iversen S, Felderhoff $\mathrm{T}$, Cartier R, Bonan R: Percutaneous aortic valve replacement for severe aortic stenosis in high-risk patients using the second- and current third- generation self-expanding CoreValve prosthesis device success and 30-day clinical outcome. J Am Coll Cardiol 2007, 50:69-76.

FI000 Factor 3.0 Recommended Evaluated by John Paraskos 24 Sep 2007

14. Wenaweser P, Buellesfeld L, Gerckens U Wenaweser P, Buellesfeld L, Gerckens U, Grube E: Percutaneous aortic valve replacement for severe aortic regurgitation in degenerated bioprosthesis: the first valve in valve procedure using the CoreValve revalving system. Catheter Cardiovasc Interv 2007, 70:760-4.

15. Grube E, Laborde JC, Gerckens U, Felderhoff T, Sauren B, Buellesfeld L, Mueller R, Menichelli M, Schmidt T, Zickmann B, Iversen S, Stone GW: Percutaneous implantation of the CoreValve selfexpanding valve prosthesis in high risk patients with aortic valve disease: The Siegburg first-in-man study. Circulation 2006, I 14:1616-24

FI000 Factor 3.0 Recommended

Evaluated by Alik Sagie 14 Nov 2006

16. Dewey TM, Walther T, Doss M, Brown D, Ryan WH, Svensson L, Mihaljevic T, Hambrecht R, Schuler G, Wimmer-Greinecker G, Mohr FW, Mack MJ: Transapical aortic valve implantation: an animal feasibility study. Ann Thorac Surg 2006, 82: II0-6.

17. Lichtenstein SV, Cheung A, Ye J, Thompson CR, Carere RG, Pasupati S, Webb JG: Transapical transcatheter aortic valve implantation in humans: initial clinical experience. Circulation 2006, I | 4:59|-6.

FI000 Factor 6.0 Must Read

Evaluated by Brian Griffin 29 Aug 2006

18. Walther T, Simon P, Dewey T, Wimmer-Greinecker G, Falk V, Kasimir MT, Doss M, Borger MA, Schuler G, Glogar D, Fehske W, Wolner E, Mohr FW, Mack M: Transapical minimally invasive aortic valve implantation multicenter experience. Circulation 2007, I I 6(Suppl I):I-240-5.

FI000 Factor 3.0 Recommended

Evaluated by Elliot Rapaport 2 Nov 2007

19. Zierer A, Wimmer-Greinecker G, Martens S, Moritz A, Doss M: The transapical approach for aortic valve implantation. J Thorac Cardiovasc Surg 2008, 136:948-53. 